\title{
PERAN SUPERVISOR DALAM PENINGKATAN MUTU PENDIDIKAN
}

\author{
Ainol \\ Email: Ainol@gmail.com \\ Universitas Islam Zainul Hasan Genggong
}

\begin{abstract}
Education is a very important thing to improve, because through the education of the nation's generation that is qualified in terms of science and technology and imtaq can be formed. To improve the quality of education, the parties involved must also be constantly improved. One of the parties that plays a role in the world of education is the school supervisor. Quality school supervisors must have a large responsibility, always develop their profession, carry out the preparation of work methods and school supervision instruments, and have a clear work program in accordance with the stipulated provisions. Management of education supervisors is a strategic element in achieving educational goals. Both the purpose of education in the national, institutional, and also curricular context.
\end{abstract}

Keywords: supervisor, education, and nation's generation 


\section{PENDAHULUAN}

Pendidikan merupakan hal yang sangat penting untuk ditingkatkan, karena melalui pendidikan generasi bangsa yang berkualitas dalam hal iptek dan imtaq dapat terbentuk. Untuk meningkatkan mutu pendidikan, maka pihakpihak yang terlibat didalamnya pun harus senantiasa ditingkatkan. Salah satu pihak yang berperan dalam dunia pendidikan adalah pengawas sekolah. Pengawas sekolah yang bermutu harus memiliki tanggungjawab yang besar, selalu mengembangkan profesinya, melakukan penyusunan metode kerja dan instrumen kepengawasan sekolah, serta memiliki program kerja yang jelas sesuai ketentuan yang telah ditetapkan. Manajemen pengawas pendidikan merupakan elemen strategis dalam pencapaian tujuan pendidikan. Baik tujuan pendidikan dalam konteks nasional, institusional, dan juga tujuan kurikuler.

Dunia persekolahan saat ini mengalami dilema, disatu sisi harus meningkatkan mutu pembelajaran, disisi yang lain menghadapi tuntutan stakeholder, sedangkan pada saat yang bersamaan, terjadi perubahan yang signifikan terhadap pertumbuhan dan perkembangan ilmu pengetahuan dan teknologi. Dalam hal ini, masyarakat menuntut agar lulusan persekolahan tidak terpojok dan teralienasi dengan perubahan yang begitu deras tersebut.

Pengawas pendidikan, dalam konteks perubahan pendidikan adalah elemen yang dapat memberikan pencerahan. Pencerahan itu bersifat komperhensif dilingkungan persekolahan. Kinerja pengawas, walaupun adakalanya bersifat teknis, tetapi memiliki kedudukan strategis dalam menciptakan situasi yang kondusif bagi pencapaian kinerja setiap elemen yang ada di sekolah, baik itu kepala sekolah, guru, laboran, pustakawan, tenaga administrasi, peserta didik dan siapa saja yang terlibat secara langsung terhadap proses pembelajaran.

Untuk mendukung kinerja guru yang memiliki kompetensi itulah, diperlukan adanya proses dan prosedur layanan bantuan kepada guru-guru dan tenaga kependidikan lainnya. Sesuai Peraturan Pemerintah Nomor 38 Tahun 1992, tentang tenaga kependidikan, pihak yang berwenang memberikan layanan bantuan kepada guru dan tenaga kependidikan lainnya, adalah 
pengawas pendidikan. Pengawas pendidikan memiliki kompetensi dan kewenangan untuk mendukung terciptanya kinerja fungsional tenaga kependidikan.

Pengawas pendidikan, berdasarkan Keputusan Menteri Negara Pendayagunaan Aparatur Negara nomor 21 Tahun 2010 tentang jabatan fungsional pengawas sekolah dan angka kreditnya, adalah (ayat 2) Pegawai Negeri Sipil (PNS) yang diberi tugas, tanggung jawab dan wewenang secara penuh oleh pejabat yang berwenang untuk melaksanakan pengawasan akademik dan manajerial pada satuan pendidikan. (ayat 4) Kegiatan pengawasan adalah kegiatan pengawas sekolah dalam menyusun program pengawasan, melaksanakan program pengawasan, evaluasi hasil pelaksanaan program, dan melaksanakan pembimbingan dan pelatihan profesional Guru.

Merujuk kepada Keputusan Menteri tersebut, dapat dikatakan bahwa pengawas pendidikan adalah pejabat fungsional yang memberikan layanan bantuan kepada personil dan lembaga pendidikan. Melalui proses dan prosedur kinerjanya, patut diduga akan memberikan pengaruh yang signifikan terhadap proses manajerial dan pembelajaran dilingkungan persekolahan.

\section{PEMBAHASAN}

\section{Kompetensi Pengawas Sekolah}

Kompetensi utama seorang Pengawas Sekolah terletak pada kemampuan personalnya. ${ }^{1}$ Persyaratan untuk semua Pengawas Sekolah, yaitu : teknikal, human, manajemen atau administratif. Ketiga kompetensi tersebut disebut gabungan ketrampilan (skill mix). Dimensi teknikal berkaitan dengan kemampuan menggunakan pengetahuan, metode, teknik, dan peralatan dalam melaksanakan Kurikulum 2006 dan sistem penilaiannya. Keterampilan manajerial mencakup perencanaan, organisasi, staffing, pendelegasian tanggung jawab, pengarahan, dan pengendalian. Lima hal tersebut merupakan fungsi dari manajemen. Keterampilan manajerial Pengawas Sekolah juga

${ }^{1}$ Glickman, C.D 1995. Supervision of Instruction, Boston: Allyn And Bacon Inc 
mencakup kemampuan menghubungkan kerja unit dengan unit yang lain bagian dari lembaga pendidikan. Kerja unit ini bisa berupa hasil kerja guru satu dengan lainnya atau kerja dari staf administrasi sebagai pendukungnya.

Ketrampilan human dalam supervisi merupakan kemampuan mempengaruhi orang lain agar mau melakukan perubahan untuk perbaikan atau peningkatan. Untuk itu seorang Pengawas Sekolah harus mampu berkomunikasi dengan baik, termasuk kemampuan menyampaikan saran dengan baik, yaitu mudah dipahami. Jadi seorang Pengawas Sekolah harus menguasai pengetahuan tentang substansi yang dipantau dan dievaluasi, memiliki keterampilan berhubungan dengan orang lain termasuk berkomunikasi, dan memiliki keterampilan dalam pengelolaannya.

Kompetensi-kompetensi yang harus dimiliki oleh pengawas sekolah dapat juga disebutkan sebagai berikut ${ }^{2}$ :

a. Mampu melakukan supervisi sesuai prosedur dan teknik-teknik yang tepat

b. Mampu melakukan monitoring, evaluasi dan pelaporan program pendidikan sesuai dengan prosedur yang tepat

c. Memahami dan menghayati arti, tujuan dan teknik supervisi

d. Menyusun program supervisi pendidikan

e. Melaksanakan program supervisi pendidikan

f. Memanfaatkan hasil-hasil supervisi

g. Melaksanakan umpan balik dari hasil supervisi

\section{Profesionalisme Pengawas Sekolah}

Profesionalisasi Pengawas Sekolah yaitu orang yang melakukan kegiatan supervisi. Ia mungkin seorang pengawas umum pendidikan, atau kepala sekolah yang karena peranannya sebagai pemimpin mempunyai tanggung jawab tentang mutu program pengajaran di sekolahnya, atau seorang petugas khusus yang diangkat untuk memimpin perbaikan suatu bidang pengajaran tertentu, seperti misalnya pendidikan jasmani, seni rupa, musik,

${ }^{2}$ Direktorat Tenaga Kependidikan, Metode dan Teknik Supervisi, Direktorat Tenaga Kependidikan, Direktorat Jenderal PMPTK, 2008, hal 20 
keterampilan-keterampilan dan lain sebagainya. ${ }^{3}$ Secara rinci sebelum mengetahui tentang profesionalisasi Pengawas Sekolah, maka terlebih dahulu mengetahui tentang peran dan fungsi seorang Pengawas Sekolah

Fungsi dan kedudukan seorang Pengawas Sekolah dalam sistem pendidikan mempunyai fungsi dan peran yang strategis dalam meningkatkan mutu pendidikan, sebab berperan banyak dalam meningkatkan mutu pendidikan.

\section{a. Peran Pengawas Sekolah}

Pendidikan merupakan suatu organisasi yang bersifar formal, struktural, dinamis dan fleksibel dimana di dalam organisasi ini harus mempunyai tujuan yang jelas, sama halnya pada umumnya tujuan dari supervisi untuk terus memperbaiki keadaan sekolah baik secara material, finansial maupun dengan hubungan sosialnya di dalam lingkungan sekolah. Tujuan supervisi ini adalah sebagai berikut ${ }^{4}$ :

1) Membina kepala sekolah dan guru-guru untuk lebih memahami tujuan pendidikan yang sebenarnya dan peranan sekolah untuk mencapai tujuan itu.

2) Memperbesar kesanggupan kepala sekolah dan guru-guru untuk mempersiapkan peserta didiknya menjadi anggota masyarakat yang efektif.

3) Membantu kepala sekolah dan guru mengadakan diagnosis secara kritis terhadap aktivitas-aktivitasnya dan kesulitan-kesulitan mengajar belajar, serta menolong mereka merencanakan perbaikan-perbaikan.

4) Memperbesar ambisi-ambisi guru untuk untuk meningkatkan mutu karyanya secara maksimal dalam bidang profesinya (keahlian) meningkatkan "achievement motive".

5) Meningkatkan kesadaran kepala sekolah dan guru-guru serta warga sekolah lainnya terhadap tata kerja yang demokratis dan kooperatif serta untuk memperbesar kesediaan untuk tolong-menolong. 
6) Membantu pimpinan sekolah untuk mempopulerkan sekolah kepada masyarakat dalam pengembangan program-program pendidikan.

7) Membantu kepala sekolah dan guru-guru untuk dapat mengevaluasi aktivitasnya dalam konteks tujuan-tujuan aktivitas perkembangan peserta didik.

8) Mengembangkan "Esprit de corps" guru-guru, yaitu adanya rasa kesatuan dan persatuan (kolegialitas) antar guru-guru.

9) Meningkatkan belajar siswa dan meningkatkan perbaikan kualitas kehidupan masyarakat.

10) Untuk memupuk kualitas kepemimpinan dalam menjamin adanya kontinyuitas dan penyesuaian kembali secara konstan program pendidikan dalam setahun tiap tahun pelajaran, tingkatan demi tingkatan dalam sistem pendidikan dari satu bidang dan isi dari pengalaman belajar lain.

11) Tujuan langsung supervisi pendidikan secara kooperatif mengembangkan tata susunan (setting) belajar-mengajar :

1. Supervisi, melalui sekalian usaha yang dapat digunakan, sebaiknya menemukan metoda-metoda belajar dan mengajar yang sudah diperbaiki.

2. Supervisi hendaknya menciptakan iklim fisik, sosial dan psikologis atau lingkungan yang mantap untuk belajar. Supervisi hendaknya mengkoordinasi dan mengintegrasikan sekalian upaya dan material perbaikan serta mengadakan kontinyuitas. 


\section{Spektrum Tenaga Kependidikan}

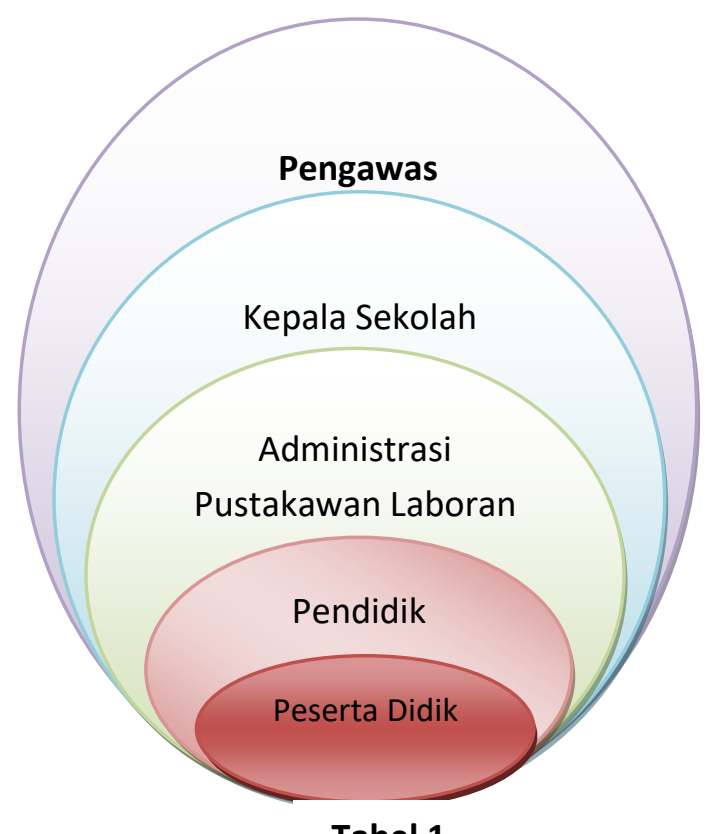

Tabel 1

\section{Tantangan Pengawas Sekolah}

a. Kondisi pengawas saat ini,

1) Rekrutmen belum dilaksanakan sesuai standar yang diharapkan

2) Latar belakang pendidikan dan kemampuan profesionalnya sangat heterogen

3) Pengawasan manajerial lebih menonjol daripada pengawasan akdemik dengan kualitas seadanya.

4) Pembinaan kemampuan profesional dan jenjang karier kurang optimal.

5) Penghargaan dan daya dukun masih kurang.

6) Citra dan wibawa akdemik masih rendah

7) Program kepengawasan belum disusun berdasarkan analisis kebutuhan sekolah

8) Laporan kepengawasan belum digunakan sebagai bahan pertimbangan pengambilan keputusan

b. Kondisi pengawas yang diharapkan,

1) Dilaksanakan profesional, yaitu secara efektif, efisien, dan produktif 
2) Memiliki kompetensi profesional

3) Komitmen tinggi terhadap tupoksi

4) Dihargai dan dilindungi

5) Keterkaitan kinerja pengawas dengan kinerja sekolah

6) Rasio jumlah pengawas dengan jumlah sekolahyang memadai

7) Daya dukung dan fasilitas yang wajar

8) Diperlukan koordinator pengawas dengan tunjangan jabatannya

9) Ada standar kualifikasi rekrutmen dan seleksi

\section{Syarat Pengawas Sekolah}

a. Untuk TK/RA dan SD/MI

1) Berpendidikan minimum sarjana (S-1) atau diploma empat (D-IV) kependidikan dari perguruan tinggi terakreditasi

2) Memiliki sertfikat pendidikan fungsional sebagai pengawas satuan pendidikan.

3) Berusia setinggi-tingginya 50 tahun sejak diangkat sebagai pengawas satuan pendidikan.

b. Untuk SMP/MTs, SMA/MA dan SMK/MAK

1) Pendidikan minimum magister (S-2) kependidikan dengan berbasis sarjana (S-1) dalam rumpun mata pelajaran yang relevan pada perguruan tinggi terakreditasi.

2) Memenuhi kompetensi sebagai pengawas satuan pendidikan yang dapat diperoleh melalui uji kompetensi dan atau pendidikan dan pelatihan fungsional pengawas pada lembaga yang tetapkan pemerintah.

c. Berstatus sebagai guru sekurang-kurangnya 8 (delapan) tahun atau kepala sekolah sekurang-kurangnya 4 (empat) tahun pada jenjang pendidikan yang sesuai dengan satuan pendidikan yang diawasi.

d. Memiliki pangkat minimum penata, golongan ruang III/c

e. Lulus seleksi sebagai Pengawas Satuan Pendidikan. 


\section{Tugas Pokok dan Fungsi Pengawas Sekolah/Madrasah}

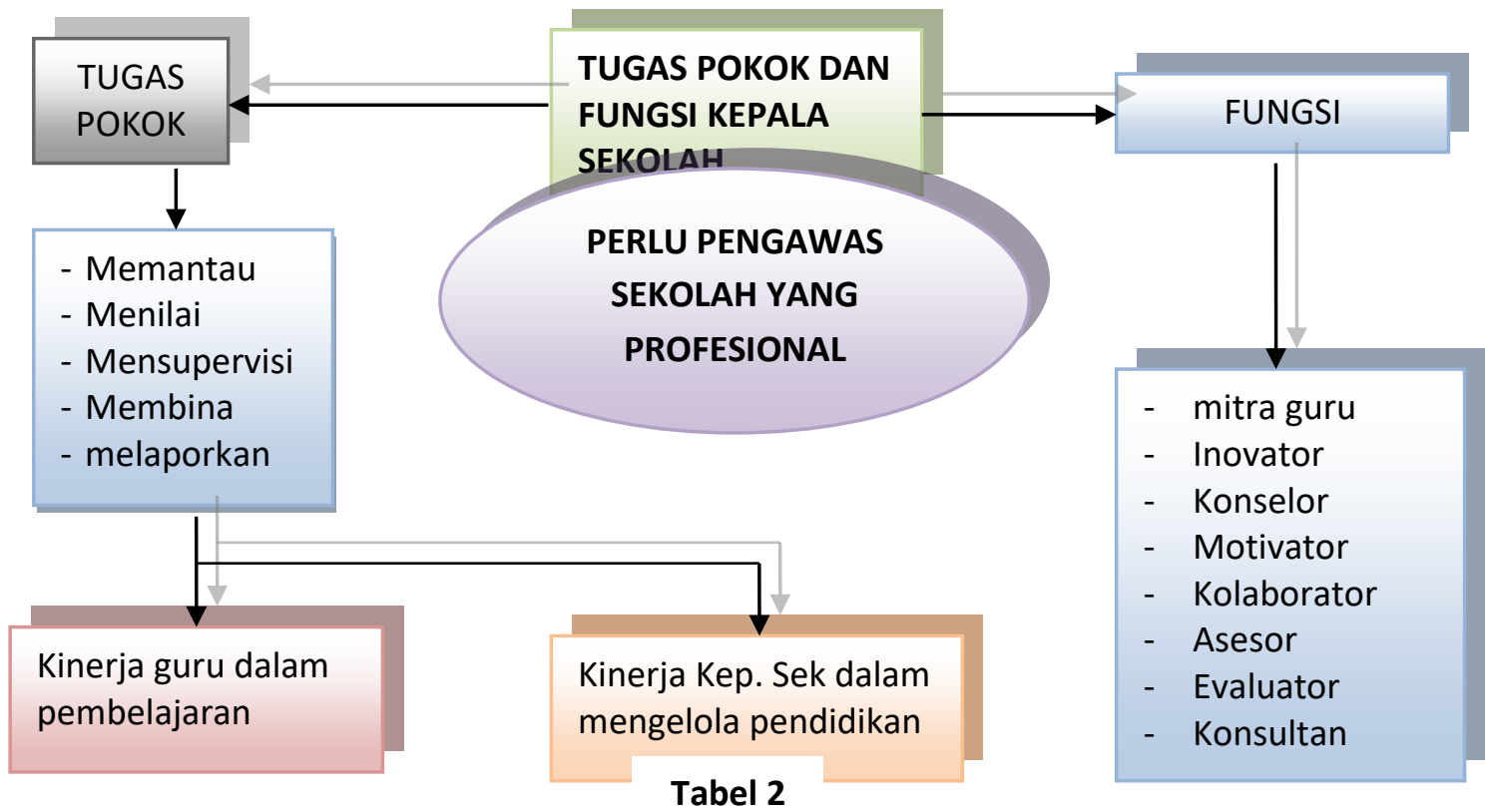

\section{Kedudukan Pengawas Sekolah}

Pengawas sekolah adalah pejabat fungsional yang berkedudukan sebagai pelaksana teknis untuk melakukan pengawasan pendidikan terhadap sejumlah sekolah yang ditunjuk/ditetapkan.

\section{Matrik Tugas Pokok Pengawas ${ }^{5}$}

\begin{tabular}{|c|c|c|}
\hline 1. Monitoring & $\begin{array}{l}\text { a. Proses dan hasil belajar } \\
\text { siswa } \\
\text { b. Penilaian hasil belajar } \\
\text { c. Ketahanan pembelajaran } \\
\text { d. Standar mutu hasil belajar } \\
\text { siswa } \\
\text { e. Pengembangan profesi } \\
\text { guru } \\
\text { f. Pengadaan dan } \\
\text { pemanfaatan sumber } \\
\text { belajar }\end{array}$ & $\begin{array}{l}\text { 1) Penjaminan/standar mutu } \\
\text { pendidikan } \\
\text { 2) Penerimaan siswa baru } \\
\text { 3) Rapat guru dan staf } \\
\text { sekolah } \\
\text { 4) Hubungan sekolah dan } \\
\text { masyarakat } \\
\text { 5) Pelaksanaan ujian sekolah } \\
\text { 6) Program-program } \\
\text { pengembangan sekolah } \\
\text { 7) Administrasi sekolah } \\
\text { 8) Manajemen sekolah }\end{array}$ \\
\hline 2. Supervisi & a. Kinerja guru & 1) Kinerja sekolah, kepala \\
\hline
\end{tabular}

${ }^{5}$ Aqib, Zainal. Standar Pengawas Sekolah/Madrasah (Kualifikasi, Kompetensi, Serttfikasi), (Bandung:CV: YRama Widya,2009), 


\begin{tabular}{|c|c|c|}
\hline & $\begin{array}{l}\text { b. Pelaksanaan } \\
\text { kurikulum/mata pelajaran } \\
\text { c. Pelaksanaan } \\
\text { pembelajaran } \\
\text { d. Praktikum/studi lapangan } \\
\text { e. Keg. Ekstrakurikuler } \\
\text { f. Penggunaan media, alat } \\
\text { bantu dan sumber belajar } \\
\text { g. Kemajuan belajar siswa } \\
\text { h. Lingkungan belajar }\end{array}$ & $\begin{array}{l}\text { sekolah, dan staf sekolah } \\
\text { 2) Pelaksanaan kurikulum } \\
\text { sekolah } \\
\text { 3) Manajemen sekolah } \\
\text { 4) Keg. Antar sekolah binaan } \\
\text { 5) Keg. In service training } \\
\text { bagi kepala sekolah, guru, } \\
\text { dan staf sekolah lainnya } \\
\text { 6) Pelaksanaan kegiatan } \\
\text { inovasi sekolah } \\
\text { 7) Penyelenggaraan } \\
\text { administrasi sekolah }\end{array}$ \\
\hline 3. Penilaian & $\begin{array}{l}\text { a. Proses pembelajaran dan } \\
\text { bimbingan } \\
\text { b. Lingkungan belajar } \\
\text { c. Sistem penilaian } \\
\text { d. Pelaksanaan inovasi } \\
\text { pembelajaran } \\
\text { e. Kegiatan peningkatan } \\
\text { kemampuan profesi guru }\end{array}$ & $\begin{array}{l}\text { 1) Peningkatan mutu SDM } \\
\text { sekolah } \\
\text { 2) Penyelenggaraan inovasi } \\
\text { di sekolah } \\
\text { 3) Akreditasi sekolah } \\
\text { 4) Pengadaan sumberdaya } \\
\text { pendidikan } \\
\text { 5) Kemajuan pendidikan }\end{array}$ \\
\hline $\begin{array}{l}\text { 4. Pembinaan/ } \\
\text { pengembangan }\end{array}$ & $\begin{array}{l}\text { a. Guru dalam } \\
\text { pengembangan media dan } \\
\text { alat bantu pembelajaran } \\
\text { b. Memberikan contoh } \\
\text { inovasi pembelajaran } \\
\text { c. Guru dalam } \\
\text { pembelajaran/bimbingan } \\
\text { yang efektif } \\
\text { d. Guru dalam } \\
\text { meningkatkan } \\
\text { kompetensi profesional } \\
\text { e. Guru dalam } \\
\text { melaksanakan penelitian } \\
\text { tindakan kelas } \\
\text { f. Guru dalam } \\
\text { meningkatkan } \\
\text { kompetensi pribadi, } \\
\text { sosial, dan pedagogik. }\end{array}$ & $\begin{array}{l}\text { 1) Kepala sekolah dalam } \\
\text { mengelola pendidikan } \\
\text { 2) Tim kerja dan staf sekolah } \\
\text { dalam dalam } \\
\text { meningkatkan kinerja } \\
\text { sekolah } \\
\text { 3) Komite sekolah dalam } \\
\text { meningkatkan partisipasi } \\
\text { masyarakat dalam } \\
\text { pendidikan } \\
\text { 4) Kepala sekolah dalam } \\
\text { melaksanakan inovasi } \\
\text { pendidikan } \\
\text { 5) Kepala sekolah dalam } \\
\text { meningkatkan } \\
\text { kemampuan } \\
\text { profesionalnya } \\
\text { 6) Staf sekolah dalam } \\
\text { melaksanakan tugas } \\
\text { administrasi sekolah } \\
\text { 7) Kepala sekolah dan staf } \\
\text { dalam kesejahteraan } \\
\text { sekolah }\end{array}$ \\
\hline $\begin{array}{l}\text { 5. Pelaporan dan } \\
\text { tindak lanjut }\end{array}$ & $\begin{array}{l}\text { a. Kinerja guru dalam } \\
\text { melaksanakan } \\
\text { pembelajaran }\end{array}$ & $\begin{array}{l}\text { 1) Kinerja sekolah, kinerja } \\
\text { kepala, dan staf sekolah } \\
\text { 2) Standar mutu pendidikan }\end{array}$ \\
\hline
\end{tabular}




\begin{tabular}{|l|l|cc|}
\hline & b. Kemajuan belajar siswa & \multicolumn{2}{|c|}{ dan pencapaiannya } \\
& c. Pelaksanaan dan hasil & 3) Pelaksanaan dan hasil \\
inovasi pembelajaran & inovasi pendidikan \\
d. Pelaksanaan tugas & 4) Pelaksanaan tugas \\
kepengawasan akademik & kepengawasan manajerial \\
e. Tindak lanjut hasil & dan hasil-hasilnya \\
pengawasan untuk & 5) Tindak lanjut untuk \\
program pengawasan & program pengawasan \\
selanjutnya & selanjutnya. \\
\hline
\end{tabular}

\section{PENUTUP}

Mutu pendidikan memiliki arti sebagai segala upaya sekolah/madrasah dalam pengelolaan secara operasional dan efisien tehadap komponen-komponen yang berkaitan dengan sekolah sehingga menghasilkan nilai tambah terhadap komponen tersebut menurut norma/ standar yang berlaku. ${ }^{6}$

Mutu sebagai tujuan atau hasil akhir yang akan dicapai pendidikan, tidak hanya melibatkan guru sebagai seorang pendidik, tetapi juga melibatkan tenaga kependidikan lainnya seperti pengawas. Pengawas merupakan mitra guru untuk mencapai proses pembelajaran, pengawas mampu memberikan bantuan kepada guru agar proses dan hasil pendidikan menjadi bermutu. Mutu pendidikan ditempat tertentu merupakan miniatur dari mutu pendidikan secara nasional, karena proses dan hasilnya mencerminkan apa yang terjadi secara nasional.

Namun demikian, dalam proses mencapai pendidikan yang bermutu itu, pengawas menjadi bagian dalam meningkatkan mutu. Mutu pengawas akan mempengaruhi mutu guru, mutu guru akan mempengaruhi mutu proses pembelajaran, proses pembelajaran yang bermutu akan menghasilkan peserta didik yang bermutu, dan pada akhirnya jika semua bersinergi akan mempengaruhi mutu pendidikan secara keseluruhan.

${ }^{6}$ Siahaan, Drs. Amiruddin, M.Pd, Rambe, Drs. H.Asli, SH., M.Pd, Muhidin, Drs,MP.d Manajemen Pengawas Pendidikan (Ciputat: Quantum Teaching, 2006), 102 


\section{Daftar Pustaka}

Aqib, Zainal. Standar Pengawas Sekolah/Madrasah (Kualifikasi, Kompetensi, Serttfikasi), (Bandung:CV: YRama Widya,2009),

Direktorat Tenaga Kependidikan, Metode dan Teknik Supervisi, Direktorat Tenaga Kependidikan, Direktorat Jenderal PMPTK, 2008,

Glickman, C.D 1995. Supervision of Instruction, Boston: Allyn And Bacon Inc Hariwung, A.J. (1989) Supervisi Pendidikan, Depdikbud, Jakarta

Siahaan, Drs. Amiruddin, M.Pd, Rambe, Drs. H.Asli, SH., M.Pd, Muhidin, Drs,MP.d Manajemen Pengawas Pendidikan (Ciputat: Quantum Teaching, 2006)

Sutisna, Oteng (1993), Administrasi Pendidikan, Dasar Teoritis untuk Praktek Profesional, Angkasa Bandung 